\title{
Sexual Orientation and Gender Identity After Prenatal Exposure to the Dutch Famine
}

\author{
Susanne R. de Rooij • Rebecca C. Painter • \\ Dick F. Swaab · Tessa J. Roseboom
}

Received: 13 September 2007 / Revised: 8 July 2008 / Accepted: 26 July 2008 / Published online: 11 September 2008

(C) The Author(s) 2008. This article is published with open access at Springerlink.com

\begin{abstract}
Sexual differentiation of the human brain has been suggested to take place through exposure to sex steroids during intrauterine development. Animal experiments have shown that interference in this process by underfeeding of the mother can result in feminization of the male offspring. We explored the possible effects of prenatal exposure to famine on sexual orientation and gender identity in humans. We used the Klein Sexual Orientation Grid to assess sexual orientation and also assessed gender identity in a group of 380 men and 472 women who were born as term singletons around the time of the 19441945 Dutch famine. Prenatal exposure to famine did not affect sexual orientation in men or in women. Three people indicated having some gender identity problems: one woman born before the famine and one man and woman exposed to famine in late gestation. In men, a later birth order was associated with a nonexclusively heterosexual identification. In conclusion, we found no evidence for a significant association between exposure to famine in utero and altered sexual orientation and gender identity. The small sample size of participants with non-exclusively heterosexual identification (possibly due to underreporting of homosexuality) may have reduced our power to detect any differences.
\end{abstract}

Keywords Dutch famine - Prenatal undernutrition . Sexual orientation $\cdot$ Gender identity

S. R. de Rooij ( $\square)$ · R. C. Painter · T. J. Roseboom Department of Clinical Epidemiology and Biostatistics, Academic Medical Centre, University of Amsterdam, Meibergdreef 9, POB 22660, 1100 DD Amsterdam,

The Netherlands

e-mail: s.r.derooij@amc.uva.nl

D. F. Swaab

Netherlands Institute for Neuroscience, Amsterdam,

The Netherlands

\section{Introduction}

Development of sexual orientation and gender identity in humans has been hypothesized to partly result from an interaction between sex hormones and the developing brain cells. Factors that interfere with this process of sexual differentiation during development in the womb may permanently influence later behavior (Swaab, 2007). Evidence for this hypothesis comes from a number of studies that have investigated the effects of prenatal exposure to atypical levels of (artificial) sex hormones, to anticonvulsants, and to stress on sexual orientation and gender identity. For example, women who were exposed to diethylstilbestrol (DES) during gestation showed increased bisexuality and homosexuality (Ehrhardt et al., 1985; MeyerBahlburg et al., 1995). Also, women who were born with congenital adrenal hyperplasia, a disease characterized by high androgen levels during fetal development, have been shown to display more gender identity problems, bisexuality, and homosexuality (Dessens, Slijper, \& Drop, 2005; Meyer-Bahlburg, Dolezal, Baker, \& New, 2008). Men and women prenatally exposed to anticonvulsants showed a higher rate of genderidentity-related problems and transsexualism (Dessens et al., 1999). Some studies have shown an association between selfreported stress during pregnancy of mothers and male homosexuality, possibly due to the effect of stress hormones on the fetal sex hormone balance (Dörner et al., 1980; Ellis \& ColeHarding, 2001). Other studies, however, failed to confirm this association (Bailey, Willerman, \& Parks, 1991; Schmidt \& Clement, 1990).

Blanchard and Ellis (2001) reported that homosexual males with older brothers weighed about $170 \mathrm{~g}$ less at birth than the heterosexual males with older brothers, a difference hypothesized to result from the progressive immunization of mothers to male specific antigens by each succeeding male fetus. An alternative explanation could be that prenatal undernutrition, for 
which low birth weight is a proxy, plays a part in this association. Possible effects of prenatal undernutrition on sexual orientation and gender identity in humans have not been studied before. In male rats, it was shown that undernutrition during the last part of gestation (days 14-20) was associated with a $23 \%$ reduction in birth weight and a 50\% reduction in the size of the sexually dimorphic nucleus of the preoptic area (SDN-POA), resulting in reduced levels of sexual activity and lower plasma testosterone levels (Anderson, Rhees, \& Fleming, 1985).

The Dutch famine birth cohort study offers a unique opportunity to explore possible effects of prenatal exposure to famine on the sexual differentiation of the brain, as was shown in male rats (Anderson et al., 1985). Because of its explorative character, we not only studied possible effects in men, but also in women.

\section{Method}

\section{Participants}

The Dutch famine birth cohort comprises 2414 men and women born as term singletons between 1 November 1943 and 28 February 1947 in the Wilhelmina Gasthuis, a hospital of the University of Amsterdam. The selection procedures and loss to follow up have been described in detail elsewhere (Painter et al., 2005; Ravelli et al., 1998). Cohort members still living in the Netherlands on 1 September 2002 and whose address was known to the investigators were eligible for participation. Of the original cohort of 2414, 160 babies had not been registered in Amsterdam at birth and were lost to follow up. A further 328 people had died, 213 people had emigrated, 157 people refused permission for the study to record their address, 125 people were not traceable to a current address by the municipalities, and 8 people requested their address be removed from the study's database. The remaining 1423 eligible people were invited to participate in the study, of whom 860 (60\%) agreed to participate. Reasons for not participating included: lack of time, lack of interest, and not being able to participate due to (mental) health problems. People who agreed to participate had mean birth weights similar to those of eligible people not participating ( $3351 \mathrm{~g}$ vs. $3358 \mathrm{~g}$ ). The study was approved by the local Medical Ethics Committee and carried out in accordance with the Declaration of Helsinki. Participants received oral and written explanation of the study aim and procedure. The study aim was given only in general terms, i.e., that the researchers wanted to know the sexuality of the participants.

\section{Design}

Exposure to famine was defined according to the daily official food rations for the general population aged $>21$ years (Trienekens, 1985). We considered fetuses to have been exposed to famine if the average daily rations during any 13 -week period of gestation were $<1000$ calories. Therefore, babies born between 7 January and 8 December 1945 were considered exposed. We used periods of 16 weeks each to differentiate between people who were exposed to famine in late gestation (born between 7 January 1945 and 28 April 1945), in mid gestation (born between 29 April and 18 August 1945), and in early gestation (born between 19 August and 8 December 1945). All cohort members born between 1 November 1943 and 6 January 1945 (born before the famine), and between 9 December 1945 and 28 February 1947 (conceived after the famine) had thus not been exposed to famine in utero and served as the control group.

\section{Procedure}

Maternal and birth characteristics were provided by medical birth records (Ravelli et al., 1998). The birth order was known, but not the sex of older siblings. Information about socioeconomic and marital status was obtained during a standardized interview. We defined current socioeconomic status according to the International Socioeconomic Index of occupational status, which is based on the participant's or their partner's occupation, whichever status was higher (Bakker \& Sieben, 1992).

To measure sexual orientation, participants were asked to complete a Dutch translation of the Klein Sexual Orientation Grid (KSOG) (Klein, Sepekoff, \& Wolf, 1985). This scale consists of four items concerning behavior (two on behavior between 12 and 17 years of age, two on present behavior), four items concerning fantasy (two on fantasies between 12 and 17 years of age, two on present fantasies), and one item concerning self-identification (heterosexual/homosexual). The participant had to score the items on a 7-point scale ranging from "exclusively with/about own sex" ( $1=$ completely homosexual) to "exclusively with/about other sex" $(7=$ completely heterosexual) for the behavior and fantasy items, and ranging from "exclusively homosexual" (1) to "exclusively heterosexual" (7) for the self-identification item. The participant could also indicate that the question of the item was not applicable to him/her (except for the self identification item). For an English translation of the KSOG in Dutch, see Appendix. Cronbach's alpha was 0.90 for the nine items of the KSOG, indicating internal consistency of the items in our study group. Gender identity was measured by an item on which the participant had to indicate to what extent he or she regarded him or herself as transsexual. This item was scored on a 3-point scale ranging from "exclusively transsexual" (1) to "a bit transsexual" (2) to "not at all transsexual" (3).

\section{Statistical Analyses}

In Table 2, the result shown on behavior between 12 and 17 years is the downwards rounded mean of the scores on the 
two items concerning this topic. The same holds for behavior currently, and fantasy between 12 and 17 years and currently. When one of the two items concerning a topic was answered with "not applicable to me" or was not filled out, the answer on the other item was taken as the mean. For the statistical analysis, the mean of the four scores on behavior between 12 and 17 years and currently was taken, resulting in the behavior dimension. When one or more items were answered with "not applicable to me" or was not filled out, the answers on the other items were taken for the calculation of the mean. The same was done for the four scores on fantasy between 12 and 17 years and currently, resulting in the fantasy dimension. We then dichotomized the three remaining dimensions (behavior, fantasy, and self identification) into exclusively heterosexual ( $0=$ all items answered with 7$)$ or non-exclusively heterosexual $(1=$ at least one item answered with a 6 or lower) for analysis, based on the fact that few participants indicated scores other than 7 . We used logistic regression analyses to compare the resulting frequencies of classes 0 and 1 , percentages of men, primiparity, and marital status between those not exposed and those exposed to famine during gestation. Possible differences in age, birth weight, and socioeconomic status were analyzed with $t$ tests. The gender-identity item was analyzed separately. Besides prenatal famine exposure, we also analyzed possible relations between sexual orientation and birth order, birth weight, socioeconomic status, and marital status. We additionally adjusted the famine analyses for these variables by adding them to the regression model. We analyzed data separately for men and women. All tests were performed two-tailed; $p$-values $<.05$ were considered to be statistically significant.

\section{Results}

Table 1 shows that of the 852 participants who completed the KSOG, 380 (45\%) were men and 472 (55\%) were women, with a mean age of 58 years (SD, 1 year). A total of 348 $(41 \%)$ participants were exposed to famine during gestation.
Mothers exposed to famine during gestation were less often primiparous and babies exposed during gestation had lower birth weights compared to those not exposed to famine.

Tables 2 and 3 show that there were no significant differences in frequencies of the scores on the KSOG dimensions behavior, fantasy, and self identification between participants exposed to famine and participants not exposed to famine. Men who were prenatally exposed to famine did not more often report non-exclusively heterosexual behavior (OR 1.2 [95\% CI 0.7-2.0]), fantasies (1.3 [0.7-2.3]) or self-identification (1.1 [0.6-1.9]) than men not exposed. Exposed women also did not more often report non-exclusively heterosexual behavior (1.2 [0.8-1.9]), fantasies (0.9 [0.6-1.3]) or selfidentification (1.0 [0.6-1.5]) than women not exposed. One $(0.3 \%)$ of the 380 men who was born before the famine and three $(0.6 \%)$ of the 472 women, of whom two were born before the famine and one exposed in late gestation, considered themselves exclusively homosexual.

A total of three participants indicated having some genderidentity problems (score 2). One was a man exposed to famine in late gestation, one was a woman born before the famine, and one was a woman exposed to famine in late gestation.

A large number of people indicated that one or more items were not applicable to him/her (score 8) or they did not fill out one or more items. Proportions for men and women who had at least one non-applicable/missing score on any item differed between exposed and not exposed men $(p=.02)$, but not between exposed and not exposed women. Men exposed to famine during gestation more often had one or more non-applicable/missing scores (54\%) compared to men not exposed (48\%), especially when exposed in late $(55 \%)$ or mid $(55 \%)$ gestation.

There were no significant associations between socioeconomic status and homosexual behavior, fantasies or selfidentification. Women who had never married more often considered themselves non-exclusively heterosexual $(\mathrm{OR}=$ $2.3, p=.03)$. In men, the birth order was positively associated with non-exclusively heterosexual identification: per child ranking later in ascending order of birth sequence the

Table 1 Maternal, birth, and adult characteristics according to prenatal exposure to the Dutch famine

\begin{tabular}{|c|c|c|c|c|c|c|c|c|c|c|c|}
\hline & \multicolumn{4}{|c|}{ Not exposed } & \multicolumn{4}{|c|}{ Exposed } & \multicolumn{3}{|c|}{ Difference } \\
\hline & $\%$ & $n$ & M & SD & $\%$ & $n$ & M & SD & B & $t$ & $p$ \\
\hline Men & 47 & 504 & & & 41 & 348 & & & 0.24 & & .09 \\
\hline Age (years) & & 504 & 58.4 & 1.2 & & 348 & 58.3 & 0.6 & & 1.28 & .20 \\
\hline \multicolumn{12}{|c|}{ Maternal and birth characteristics } \\
\hline Primiparity & 38 & 504 & & & 31 & 348 & & & -0.33 & & .03 \\
\hline Birth weight (g) & & 504 & 3416 & 463 & & 348 & 3259 & 463 & & 4.85 & .00 \\
\hline \multicolumn{12}{|l|}{ Adult characteristics } \\
\hline Socioeconomic status & & 497 & 49 & 14 & & 343 & 51 & 14 & & -1.34 & .18 \\
\hline Ever married & 91 & 502 & & & 93 & 348 & & & -0.33 & & .20 \\
\hline
\end{tabular}




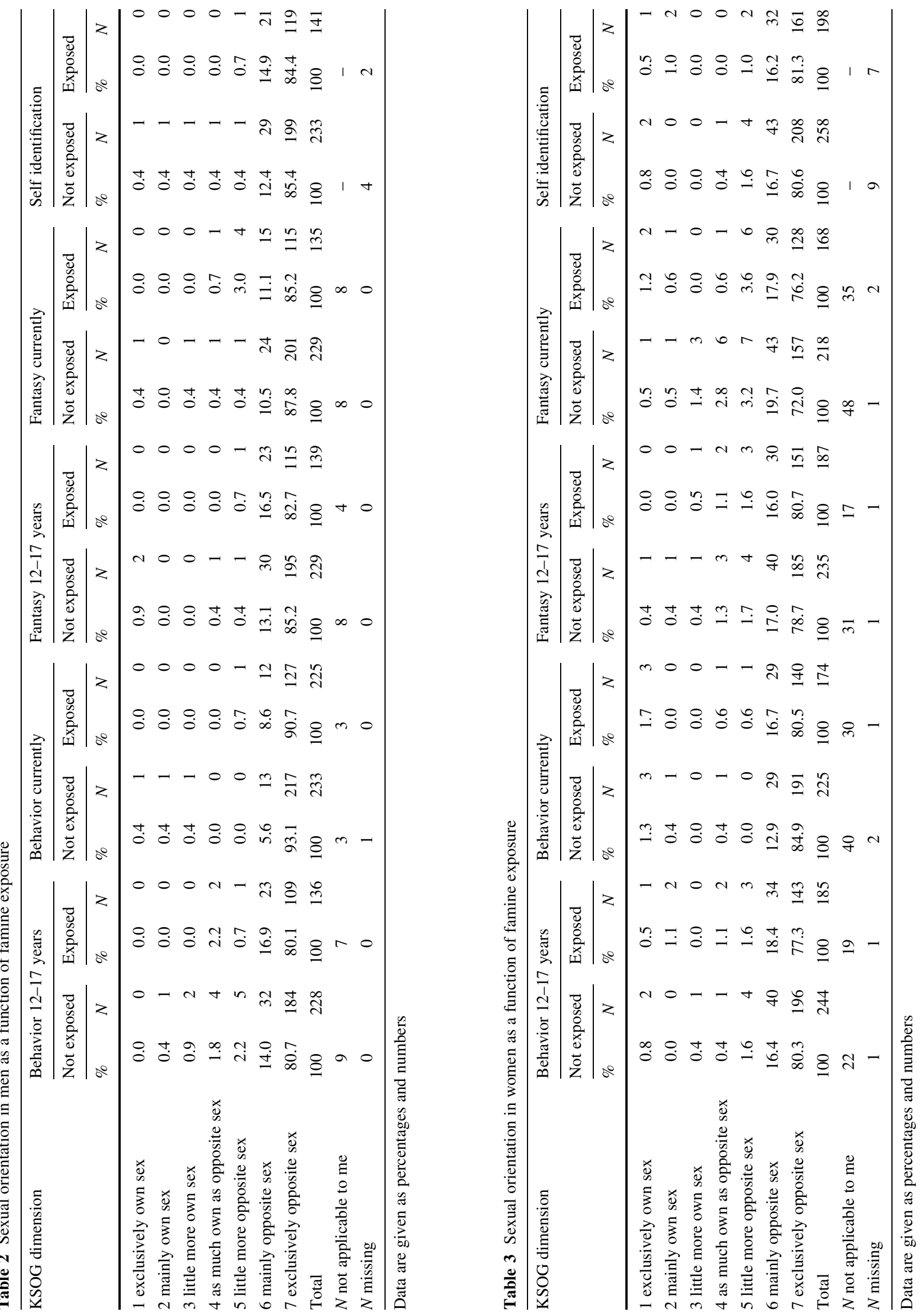


OR for a non-exclusively heterosexual identification was 1.1 ( $p=.04)$. Birth weight of men also had a small effect. Per kilo increase in birth weight the OR for a non-exclusively heterosexual identification was 1.7 ( $p=.07$, adjusted for birth order). Adjusting the famine analyses for the variables birth order, birth weight, socioeconomic status, and marital status did not change the results.

\section{Discussion}

We found no effect of prenatal exposure to famine on sexual orientation and gender identity. Men and women exposed and not exposed to famine in utero were similar in terms of hetero/ homosexual behavior, fantasies, and self-identification and gender identity.

In our study group, the prevalence of men who identified themselves as exclusively homosexual was $0.3 \%$, while in women it was $0.6 \%$. This is much lower than the mean prevalence of $7 \%$ in men and $6 \%$ in women in the general Dutch population as reported by the Rutgers Nisso group, the Dutch Institute for Social Sexual Research (Bakker \& Vanwesenbeeck, 2006). An explanation for this large discrepancy could be that, in this somewhat older age-group, declaring oneself homosexual may still be a larger taboo than it is among younger people. Another explanation could be that participants felt a lack of privacy completing the questionnaire, because there was almost always a nurse nearby. These explanations could also explain the large number of people that used the "not applicable to me" option to answer items or did not fill out items at all. We tried to minimize the number of missing topics by taking the non-missing item as the mean when the other one of the two items concerning a topic was answered with "not applicable to me" or was not filled out, although this handling of missing items could have inflated non-heterosexuality because of the transient experimentation that may go on in adolescence. On the other hand, our results match those of another study among younger individuals that used the KSOG to assess sexual orientation and also found that nearly all (292 of 294) subjects reported predominant or exclusive heterosexual behavior and feelings and were self identified heterosexuals (Dessens et al., 1999).

Despite the probable underreporting of homosexuality, the validity of our data was supported by the association we found between the unmarried status of women and a non-exclusively heterosexual identification. Also, although we had no data on the number of preceding boys or girls, the number of preceding children was positively associated with a nonexclusively heterosexual identification. This result probably reflects the association between a greater number of older brothers and homosexuality, the so-called fraternal birth order effect (Blanchard, Zucker, Siegelman, Dickey, \& Klassen,
1998). The fraternal birth order effect has been suggested to result in a lower birth weight (Blanchard \& Ellis, 2001). Unexpectedly, however, we found a weak association between higher birth weight and a non-exclusive heterosexual orientation in men. This is opposite to the finding of Blanchard and Ellis (2001) that homosexual males weighed about $170 \mathrm{~g}$ less at birth than heterosexual males in a much larger population, and may thus be an accidental finding.

No participants indicated being exclusively transsexual. The prevalence for male-to-female transsexuals in the Netherlands is $1: 11,900$, and for female-to-male transsexuals is 1:30,400 (Bakker, Van Kesteren, Gooren, \& Bezemer, 1993). Therefore, even if transsexualism were increased 10 -fold in groups of people exposed to undernutrition than in the general population, the chance of finding an effect of prenatal exposure to famine on transsexuality in our cohort was small.

In conclusion, we did not find that exposure to famine in utero permanently affects the development of sexual orientation and gender identity. The small sample size of participants with non-exclusively heterosexual identification (possibly due to underreporting of homosexuality) reduced our power to detect any differences.

Open Access This article is distributed under the terms of the Creative Commons Attribution Noncommercial License which permits any noncommercial use, distribution, and reproduction in any medium, provided the original author(s) and source are credited.

\section{Appendix}

Translation of the Dutch Klein Sexual Orientation Grid (KSOG)

\section{Item Question}

1 Between the age of 12 and 17 years, with whom did you fall in love?

2 With whom do you fall in love now?

3 Between the age of 12 and 17 years, with whom did you have sexual contacts?

$4 \quad$ With whom do you have sexual contacts now?

5 Between the age of 12 and 17 years, whom were your romantic fantasies about?

6 About whom are your romantic fantasies now?

7 Between the age of 12 and 17 years, whom were your sexual fantasies about?

8 About whom are your sexual fantasies now?

9 To what extent do you regard yourself as homosexual or heterosexual?

The response options ranged from "1" (exclusively with/about own sex/homosexual) to "7" (exclusively with/about other sex/heterosexual) to "not applicable to me" 


\section{References}

Anderson, D. K., Rhees, R., \& Fleming, D. (1985). Effects of prenatal stress on differentiation of the sexually dimorphic nucleus of the pre-optic area of the rat brain. Brain Research, 332, 113-118.

Bailey, J. M., Willerman, L., \& Parks, C. (1991). A test of the maternal stress theory of human male homosexuality. Archives of Sexual Behavior, 20, 277-293.

Bakker, B., \& Sieben, I. (1992). Maten voor prestige, sociaaleconomische status en sociale klasse voor de standaard beroepenclassificatie 1992. Sociale Wetenschappen, 40, 1-22.

Bakker, A., Van Kesteren, P. J. M., Gooren, L. J. G., \& Bezemer, P. D. (1993). The prevalence of transsexualism in The Netherlands. Acta Psychiatrica Scandinavica, 87, 237-238.

Bakker, F., \& Vanwesenbeeck, I. (2006). Seksuele gezondheid in Nederland 2006. Delft: Eburon.

Blanchard, R., \& Ellis, L. (2001). Birth weight, sexual orientation and the sex of preceding siblings. Journal of Biosocial Science, 33, 451-467.

Blanchard, R., Zucker, K. J., Siegelman, M., Dickey, R., \& Klassen, P. (1998). The relation of birth order to sexual orientation in men and women. Journal of Biosocial Science, 30, 511-519.

Dessens, A. B., Cohen-Kettenis, P. T., Mellenbergh, G. J., van de Poll, N., Koppe, J. G., \& Boer, K. (1999). Prenatal exposure to anticonvulsants and psychosexual development. Archives of Sexual Behavior, $28,31-44$.

Dessens, A. B., Slijper, F. M., \& Drop, S. L. (2005). Gender dysphoria and gender change in chromosomal females with congenital adrenal hyperplasia. Archives of Sexual Behavior, 34, 389-397.

Dörner, G., Geier, T., Ahrens, L., Krell, L., Münx, G., Sieler, H., et al. (1980). Prenatal stress as possible aetiogenetic factor of homosexuality in human males. Endokrinologie, 75, 365-368.
Ehrhardt, A. A., Meyer-Bahlburg, H. F. L., Rosen, L. R., Feldman, J. F., Veridiano, N. P., Zimmerman, I., et al. (1985). Sexual orientation after prenatal exposure to exogenous estrogen. Archives of Sexual Behavior, 14, 57-77.

Ellis, L., \& Cole-Harding, S. (2001). The effects of prenatal stress, and of prenatal alcohol and nicotine exposure, on human sexual orientation. Physiology \& Behavior, 74, 213-226.

Klein, F., Sepekoff, B., \& Wolf, T. J. (1985). Sexual orientation: A multi-variable dynamic process. Journal of Homosexuality, 11, $35-49$.

Meyer-Bahlburg, H. F., Dolezal, C., Baker, S. W., \& New, M. I. (2008). Sexual orientation in women with classical or non-classical congenital adrenal hyperplasia as a function of degree of prenatal androgen excess. Archives of Sexual Behavior, 37, 85-99.

Meyer-Bahlburg, H. F. L., Ehrhardt, A. A., Rosen, L. R., Gruen, R. S., Veridiano, N. P., Vann, F. H., et al. (1995). Prenatal estrogens and the development of homosexual orientation. Developmental Psychology, 31, 12-21.

Painter, R. C., Roseboom, T. J., Bossuyt, P. M., Osmond, C., Barker, D. J., \& Bleker, O. P. (2005). Adult mortality at age 57 after prenatal exposure to the Dutch famine. European Journal of Epidemiology, 20, 673-676.

Ravelli, A. C. J., van der Meulen, J. H. P., Michels, R. P. J., Osmond, C., Barker, D. J., Hales, C. N., et al. (1998). Glucose tolerance in adults after prenatal exposure to famine. Lancet, 351, 173-177.

Schmidt, G., \& Clement, U. (1990). Does peace prevent homosexuality? Archives of Sexual Behavior, 19, 183-187.

Swaab, D. F. (2007). Sexual differentiation of the brain and behavior. Best Practice and Research Clinical Endocrinology and Metabolism, 21, 431-444.

Trienekens, G. (1985). Tussen ons volk en de honger. Utrecht: Matrijs. 